\title{
ADVOCATING FOR THE INCLUSION OF OPERATIC \\ COLLABORATIVE PIANO CURRICULA IN HIGHER EDUCATION: \\ INFORMING CURRICULA THROUGH LIVED EXPERIENCE
}

\section{S. van Zyl*}

Doctor of Music with Music Performance

https://orcid.org/0000-0002-4207-3924

\section{A. Cupido*}

Associate Professor in Classical Singing, Opera and Vocal Pedagogy

School of Music

https://orcid.org/0000-0001-6813-6877

${ }^{*}$ North-West University

Potchefstroom, South Africa

\section{ABSTRACT}

The purpose of this article was to examine how the lived experiences of five professional collaborative pianists during the 35th International Hans Gabor Belvedere Singing Competition, that was held in Cape Town in 2016, could inform the inclusion of new curricula for specialised operatic collaborative piano modules in tertiary institutions. Based on the literature reviewed and themes that emerged from the data, a curriculum could include the following aspects: a knowledge of the rules of lyric diction in foreign languages; excellent sight-reading skills; knowledge of the art of orchestral reduction and repertoire; the ability to transcribe and reduce full opera scores. One personal skill that is not often developed and should also be included is the ability of a pianist to evince empathy when working with singers.

Keywords: collaborative pianism, opera training, higher education, opera répétiteur, Belvedere Singing Competition

\section{INTRODUCTION AND BACKGROUND}

While South African tertiary institutions have produced several internationally acclaimed concert pianists as well as pianists who frequently collaborate with opera singers, there is currently no specialised degree or course work in operatic collaborative piano training in the country. Many institutions offer courses such as accompaniment or ensemble work, but "none offers a stream of performance study dedicated to the training of répétiteurs for the opera or musical theatre fields" (De Koker 2019, 2). Nonetheless, noteworthy pianists and répétiteurs like Albie van Schalkwyk, Elna van der Merwe, Laetitia Orlandi, Mathilda Hornsveld and José 
Dias have acquired the necessary skill set in order to successfully collaborate with opera singers specifically. Currently, the number of successful opera singers that South African tertiary institutions produce far exceeds the number of operatic collaborative pianists. This can be attributed to the fact that no specialised courses in this field are offered locally and this problem is also compounded by the fact that South Africa lacks an opera industry that would provide sustainable work for répétiteurs.

In South Africa the only surviving full-time opera company is Cape Town Opera (CTO), which operates with a small subsidy from the Western Cape local government and virtually no subsidy from the South African government. Elise Brunelle, former Managing Director of Cape Town Opera, states that Cape Town Opera does not have the financial resources to employ a full-time répétiteur at the moment. She adds that tertiary music institutions in South Africa are not producing pianists who specialise in this field. As a result, CTO has to rely on grants to import experienced répétiteurs for short periods of time to work on specific productions (Brunelle 2019). The Guildhall School of Music and Drama in London and the Boston Conservatory at Berklee University in the United States of America both offer specialised training for pianists who wish to become opera répétiteurs. These institutions provide courses that include "an overview of the history of opera, the didactics of singing, language/diction modules, and practical internships within the opera division of the school” (De Koker 2019, 2). In conversations with Dr Tinus Botha and Dr Waldo Weyer, both currently Associate Professors in Piano at North-West University in Potchefstroom as well Jeremy Silver, Associate Professor and Director of Opera at the University of Cape Town, the authors have ascertained that there is a desire to make changes to the curricula at their respective institutions to provide courses offering specialised training for opera répétiteurs. Although the lack of full-time opera companies (beside CTO) in South Africa may suggest that there is no need to provide training for répétiteurs, many communities both in rural areas and city centres still undertake on operatic training and present performances nationally.

Although opera has always been associated with the "musical preferences of the upperclass white population of the country" (Roos 2014, 2), since the 1930s opera has become an integral part of the cultural expression of all racial and ethnic groups in South Africa. This is evident in the performances of the Eoan group (a mixed-race group of opera singers established in the 1930s), the outreach work done nationally by Cape Town Opera and in the popularity of performances in this genre among thousands of young scholars in predominantly black schools who participate in the South African School Choral Eisteddfod (Sasce) (Roos 2014; Dzorkpey, Potgieter, and Kruger 2013; Brunelle 2019; Pooley 2020). In her doctoral thesis Dr Hilda Roos, the General Manager of the Africa Open Institute for Music, Research and Innovation at 
Stellenbosch University, states that it is inevitable that there will be an increase in the number of opera singers produced in South Africa, especially among black singers, as a result of the training provided in tertiary institutions and in other training facilities (Roos 2010). Taking all of these factors into account one can posit that there is potential for growth in the opera industry (including the immense potential for job creation) in South Africa and in order to support the singers, attention needs to be given to the training of répétiteurs.

As already mentioned, notable pianists have successfully collaborated with opera singers despite the lack of specialised operatic collaborative courses in South Africa. An example of the proficiency of these pianists was evident during the preliminary rounds of the 35th International Hans Gabor Belvedere Singing Competition held for the first time in South Africa at venues in Cape Town, South Africa in July 2016.

\section{OVERVIEW OF THE $35^{\text {th }}$ INTERNATIONAL HANS GABOR BELVEDERE SINGING COMPETITION}

The Hungarian conductor, Hans Gabor (1924-1994), was the long-term manager of the Wiener Kammeroper and founder of the Belvedere Singing Competition. For several years the competition took place only in Austria but in recent years the competition has been held outside of Vienna, for example, in the renowned opera houses of Amsterdam in 2013 and Düsseldorf in 2014. ${ }^{1}$ Four South Africans reached the final rounds in the 34th Competition in 2015, with Levy Sekgapane attaining $1^{\text {st }}$ place. Soprano Pretty Yende won the 2009 competition; Hlengiwe Mkhwanazi took the 2nd prize in 2013 and Siyabulela Ntlale came 2nd in 2014. After the success of these South African singers, it became evident to the organisers that there is a wealth of vocal talent in South Africa and a decision was subsequently taken to host the competition in South Africa. ${ }^{2}$ In 2016 the competition was held in Africa for the first time at the Baxter Theatre in Rondebosch and at the Opera House at the Artscape Theatre Centre in Cape Town. The significance of this competition is that it acts as a "singers' stock exchange" to provide professional services for young singers, casting directors, agencies and opera houses. ${ }^{3}$ The main requirement for the singers of this competition was to present arias from the vast operatic repertoire.

In order to compete singers had to prepare arias from a wide range of music in the operatic canon. With a variety of 50 to 60 arias per voice type (soprano, mezzo, tenor and baritone), the Belvedere required the singer to prepare five arias in total: two compulsory arias (to be selected from a prescribed list) and three other arias of the singer's own choice (which could also be selected from the prescribed list). This huge number of arias left not only the orchestra librarian with approximately 300 arias to prepare, but the five piano accompanists were also required to 
know and perform them (McEwan 2016). The five South African pianists who played for the Belvedere Competition held in 2016 were Mathilda Hornsveld, Laetitia Orlandi, Albie van Schalkwyk, José Diaz and Elna van der Merwe. They have vast past experience in playing for many competitions in South Africa. Later in this article the authors will present more information about each pianist (who were the participants in this study).

The accompanists were contracted for approximately five days during the competition and were challenged with the daunting task of having to learn a wide variety of opera arias, since the singers could choose any single aria from a multitude of options. The competition repertoire included opera arias by a range of composers from the Baroque to the 20th century. Each singer selected five arias from a list of prescribed repertoire when registering for the competition. All singers participated in the first round. Participants were assigned an accompanist and rehearsal time was limited. Many singers were eliminated as the competition progressed and each pianist subsequently rehearsed each new aria with the singer who progressed to the next round. The uncertainty the pianists faced while having to prepare this huge selection of repertoire made their task extremely challenging (Van Schalkwyk 2017).

Other South African singing competitions (in which many of these five Belvedere accompanists had participated before), such as the ATKV Musiqanto Competition, and the SAMRO and UNISA vocal competitions, usually require that the singer perform several rounds of music including art song, contemporary African compositions and arias from the opera repertoire. What makes playing for the Belvedere competition different from these local competitions is that the repertoire consists exclusively of operatic arias. During a singing competition such as the Belvedere, the pianists need to have a comprehensive knowledge of the various aspects of performance practice and interpretation, including the various stylistic periods within the operatic genre. In opera houses in Europe répétiteurs mostly accompany singers in these types of competitions (Hornsveld 2017). These répétiteurs have specialised training in the operatic literature and are exposed to an abundance of repertoire on a daily basis.

In order to accompany a competition of this calibre, and to be prepared in a short amount of time, the pianists needed to be extremely familiar with the operatic repertoire in its entirety, which was problematic for the pianists engaged. In Europe this problem does not arise, since répétiteurs who are employed by opera houses, and are consequently familiar with the repertoire, are engaged to play for the competition. In South Africa currently there are no répétiteurs engaged on a full-time basis by any opera company and this was also the case in 2016. Based on the success of the performances by the pianists and vocalists in the earlier rounds of the competition held at the Baxter Theatre in Cape Town, it was evident that although these pianists may not have been familiar with all the music repertoire beforehand, they used 
their expert skills to facilitate those successful performances. The accompanists had to draw on their experience as proficient collaborative pianists in order to best support the singers. It would be pertinent to explore the lived experiences of these pianists in determining what it would take in order to establish operatic collaborative piano curricula in South Africa. Drawing from the literature as well as the lived experiences of these pianists could help inform the development of new curricula.

\section{METHOD}

The aim of this research was to gain insight into the way that five vocal collaborative pianists made sense of their lived experiences during the 35th International Hans Gabor Belvedere Singing Competition and, in doing so, inform the development of new curricula in operatic collaborative piano courses in higher education. Understanding their lived experiences could provide insight into the qualities and skill set that a successful collaborative pianist might possess. In order to explore these lived experiences, the authors employed an interpretative phenomenological analysis (IPA).

The current study is qualitative in nature. According to Creswell $(2014,185)$ and Tracy (2013, 28-29), qualitative researchers collect data directly from the participants through individual face-to-face, semi-structured interviews utilising open-ended questions so that they may elicit a "rich, thick description" of the participants' experiences. This study was grounded on those principles. A qualitative design, as suggested by Creswell $(2014,186)$, Maree (2007, $297)$ and Smith, Flowers, and Larkin $(2009,345)$ allowed the authors to explore the meaning that the five collaborative pianists assigned to their unique lived experiences during the 35th Belvedere Singing Competition. The authors interpreted the meaning ascribed to these experiences through an interpretivist paradigm. Maree $(2007,60)$ states that:

"The ultimate aim of interpretivist research is to offer a perspective on a situation and to analyse the situation under study to provide insight into the way in which a particular group of people make sense of their situation or the phenomena they encounter."

After collecting data by conducting semi-structured, person-to-person interviews, the authors analysed the data using a step-by-step guideline by Smith et al. (2009, 81-103). These six steps were:

“i. Reading and re-reading

ii. Initial coding

iii. Developing emergent themes

iv. Searching for connections across the emergent themes of each separate case 
v. Moving to the next case

vi. Looking for patterns across cases."

The responses of the participants were transcribed verbatim, followed by the coding process, the organising, integrating and interpreting of the data as described by Reid, Flowers and Larkin $(2005,22)$ and Guest et al. $(2020,285)$. Tracy $(2013,189)$ suggests that coded data capture the essence of the particular phenomenon pertinent to each participant by marking the data segments with symbols, descriptive words, phrases and unique identifying names. In this study the authors searched for pertinent statements that captured an essence of each lived experience and subsequently coded it (or gave it a label). The authors also endeavoured to first examine each individual case in detail before searching for similarities and differences across the cases. According to Creswell (2014, 199-200), a cross-case analysis entails the interpretative work of the researcher into drawing the emergent themes together in order to emphasise the most interesting and important aspects of the participant's experience.

After we identified various codes, we looked for similarities in the codes per case and grouped them into categories as suggested by Reid et al. $(2005,23)$. Categories which then related to each other were then grouped into themes. The main themes that emerged from the transcriptions were identified from the in-depth interviews. We integrated these themes into the findings of this article by using verbatim responses, as suggested by Kumar (2014, 317-18), to keep the original tenor of the participants' responses. For the purposes of this article only the data collected from the cross-case analysis and presented as superordinate (emergent themes shared by all participants) and corresponding themes (themes shared by at least two participants) were used to inform the implications of the findings that would suggest the qualities and skills required of an operatic collaborative pianist to be trained in tertiary institutions.

According to Creswell (2014, 202), a prolonged engagement and persistent observation will guarantee the building of trust with the participants. One of the authors was in regular contact with the participants throughout the interview process and consulted with them constantly throughout the process. Besides ensuring the trustworthiness of the data, Creswell $(2014,203)$ also recommends the triangulation of different data sources, methods, investigators and theories to enhance the validity of the data. The authors conducted member checking and constantly reported the themes to each other and reflected on this process with reference to the literature.

The authors followed the procedural rules and ethical guidelines set out by Kumar (2014, 284-85) by informing the potential participants of the purpose of this study. Each participant 
was given a letter of informed consent to read and sign as well as information that outlined the purpose of the research. After submitting an application including letters of informed consent from the participants, the authors received permission from the North-West University ethics committee to proceed with the research. The participants allowed their real names to be used for the purposes of this study. Since these are highly qualified pianists and experts in their fields, associating their names with the data added validity to the data. The authors did, however, respect their privacy by not publishing information they deemed private, as recommended by Tracy $(2013,243)$. Another ethical issue that the authors respected was not coercing the participants into participating in the research. We therefore provided the five participants access to the research at all times and gave them the choice to withdraw at any time for any reason. As researchers we undertook to ensure correct and unbiased reporting of the findings and took special care to ensure that no participant was harmed in any way at any stage during the research, and avoided any form of deception of the participants in the study (Creswell and Poth $2017,55-58)$.

\section{PARTICIPANTS ${ }^{4}$}

\section{Mathilda Hornsveld}

Mathilda graduated with a BMus (Performers) degree from the University of Pretoria and subsequently joined the Performing Arts Council of the Transvaal (PACT) in 1980. She worked as répétiteur, coach, backstage conductor and chorus master on all major opera productions for the State Theatre until 1993. During her tenure as Chorus Master from 1997 on an ad hoc basis until the closure of the theatre in 2000 , she also appeared as assistant conductor for various musicals, conducting some of the performances every week. During her time at the State Theatre she did two workshop operas, and while in Windhoek she conducted two productions. She worked with famous conductors like Leo Quayle, Edgar Cree, David Tidboald, Giovanni Bartoli and Alain Lombard, to name a few.

\section{Laetitia Orlandi}

Laetitia passed her BMus and MMus Hons (cum laude) degrees at the University of Pretoria. She also obtained the Performer's Licentiate in Chamber Music, the Performer's Licentiate in Vocal Accompaniment and the Performer's Licentiate in Music (cum laude) at the University of South Africa. The MMus (Performing Arts) (cum laude) from the University of Pretoria followed. She is currently studying for her $\mathrm{PhD}$ degree at the North-West University in Potchefstroom. 
She is a professional pianist, accompanist, répétiteur and has been a rehearsal pianist for various opera productions since 1998 in South Africa. She twice appeared as Chairperson of the Shadow Jury for the 5th UNISA National Piano Competition, as well as the 13th UNISA International Piano Competition. She was an official piano accompanist for the 1st UNISA National Singing Competition as well as the 5th and the 6th UNISA International Voice Competition.

\section{Elna van der Merwe}

Elna studied piano and organ at the University of Stellenbosch and passed her BMus Honours degree (cum laude). She won several awards and competitions and performed as soloist with the University of Stellenbosch Symphony Orchestra (USSO) as well as the Cape Town Philharmonic Orchestra (CPO). She was a full-time accompanist and part-time piano lecturer at the University of Stellenbosch Conservatory during the period 1989-2001. She then performed as an ad hoc piano performer and is a sought-after collaborative artist for local and international artists such as Michelle Breedt (mezzo soprano), Douglas Masek (saxophonist), Maria Kliegel (cellist) and Susan Milan (flautist). She resigned from her full-time post as accompanist and part-time piano lecturer at the University of Stellenbosch Conservatory in 2001.

\section{José Dias}

José Dias was born in Fafe (Portugal) and started piano lessons at the age of 12. He travelled to South Africa in 2001 to pursue his musical studies at the University of Stellenbosch, obtaining his BMus Honours (cum laude) and specialising in solo piano performance. He continued his studies at the Hochschule für Musik und Theater in Zürich (Switzerland). He then took up a permanent position as répétiteur at Cape Town Opera until 2011. His freelance performing career started in 2011 and he performs regularly in all major concert halls in South Africa, as well as major arts festivals. He is involved as répétiteur, vocal coach and musical director in opera productions, and is still a regular collaborator and artist with the CTO African Angels production, which has been touring internationally since 2013 to popular and critical acclaim.

\section{Albie van Schalkwyk}

Albie van Schalkwyk completed his BMus degree at the University of Cape Town under the tutelage of Lamar Crowson. After that he spent five years in London studying with Geoffrey Parsons, Gwenneth Pryor and Martino Tirimo. During this period, he won the UNISA Overseas Scholarship as well as first prize in the SABC Music Prize Piano Competition. He was 
appointed Associate Professor in Piano and Chamber Music at the College of Music, UCT in 2009.

His interest in vocal music and the art song in particular has led to many fulfilling concert partnerships with singers, culminating in the formation of the Songmakers' Guild in 1994 - a Cape Town society which provides a regular platform for performers in the field of the art song. He worked as répétiteur for the Vocal Department of the Mozarteum University in Salzburg, Austria (2002/3). He completed his PhD in music at the University of the Free State in 2012.

\section{THE VOCAL COLLABORATIVE PIANIST}

It has been mentioned already that the five participants faced the daunting task of accompanying singers in an international opera competition when only full-time répétiteurs based at opera houses in Europe have traditionally done so in the past. Those répétiteurs are not only familiar with the vast operatic repertoire, but also have a solid understanding of the performance practices of the various aspects of the genre. During the 35th Belvedere Competition held in Cape Town the five pianists needed to demonstrate the necessary skills to ensure successful performances and showing their understanding of style, performance practice and also their accompaniment proficiency. In order to better understand what might prepare a collaborative pianist for an international singing competition, the authors reviewed the literature pertaining to the fundamental skills required of a proficient vocal collaborative pianist. The literature on the need to develop music curricula on vocal collaboration in tertiary institutions in South Africa is limited.

In her thesis entitled "Collaborative Pianists in South Africa: Comparative and PracticeBased Perspectives with Reference to Musical Theatre", Jessica de Koker (2019) confirms the lack of training at universities in South Africa for pianists wanting to specialise as répétiteurs either in opera or musical theatre. She focuses on collaborative pianists wanting to specialise in musical theatre and, after examining the shortcomings of the current offerings at various institutions, she provides valuable insights into the ways in which collaborative piano courses directed at musical theatre and internship opportunities could be integrated into higher education in South Africa. She hypothesises that positive changes to the BMus Hons degree at Stellenbosch University could be made by adapting their modules in the following ways (Table 1) to accommodate new coursework for collaborative pianists intending to work in musical theatre: 
Table 1: New Honours Coursework suggested by De Koker $(2019,40)$.

\begin{tabular}{|l|c|}
\hline \multicolumn{1}{|c|}{ Module description } & Credit distribution \\
\hline $\begin{array}{l}\text { Specialization module: Collaborative Piano Studies } \\
\text { (includes sight-reading, improvisation development and internship) }\end{array}$ & 50 credits \\
\hline Voice Coaching and Conducting & 10 credits \\
\hline History of Musical Theatre & 10 credits \\
\hline Basic Arranging and Orchestration & 10 credits \\
\hline Keyboard Technology & 10 credits \\
\hline Research Paper & 30 credits \\
\hline Total: & 120 credits \\
\hline
\end{tabular}

To our knowledge, there is no literature on the ways in which similar offerings for training in operatic accompaniment could be integrated into the curricula. Furthermore, the authors could not find any studies on how the lived experiences of collaborative pianists can be used to inform new curricula in higher education. This study therefore contributes to filling this gap in the training of collaborative pianists.

\section{FUNDAMENTAL SKILL REQUIREMENTS OF A PROFICIENT VOCAL COLLABORATIVE PIANIST}

High expectations and serious responsibilities are demanded of the pianist who collaborates with other musicians/singers, especially during competitions and concerts. Garrett and Reynolds $(2017,557)$ write:

"Singers are dependent in auditions on the excellence and preparedness of collaborative pianists. These pianists, one hopes, have keen sight-reading skills, vast knowledge of the operatic and song repertoires, and lots of experience at partnering auditions without rehearsal, while still providing a performance that not only supports the singers, but also allows them to sing at their very best."

Echoing these sentiments, a number of pianists, including Philip Cranmer (1970), Martin Katz (2009), Gerald Moore (1944), (Demarest 1964) and others have written widely about the art of accompaniment. They emphasise the necessary musical skills, competencies and challenges. Katz suggests that, when collaborating with a singer, the pianist must serve as the designer as well as the director (Katz 2009, 39). This entails that the pianist is equally responsible for the musical choices made along with the singer when focusing on the delivery and expressivity of the text, word painting, tempi, dynamic variation and other interpretative nuances. This will enable the pianist to develop a better understanding and appreciation of the text and to accentuate the meaning of the text in performances (Katz 2009, 39).

Pianists are advised by $\operatorname{Katz}(2009,39)$ to take the following steps to facilitate successful 
collaboration with the singer: study the text by reading it out aloud; mark the vocal line of the score according to the specific sentence structure; notice and address any special features, such as a surprise, or where there is a question or answer in the text; and lastly, take note of the author's specific choice of words (which entails some level of multilingualism). He asserts that the role of the accompanist must encompass a performance that complies with the composer's requirements; reading and responding according to the performance partners' emotional and physical needs; protecting the poet's intentions; and lastly, meeting the accompanist's own needs (Katz 2009, 3).

Warren Jones was a vocal collaborative pianist of note who possessed the necessary skill set including all the aspects of musicianship. Jones highlights the fact that the singer on stage performs with his or her body, whereas the accompanist plays a machine (Epperson 2011, 1819). This also alludes to the fact that the singer's instrument could be more prone to emotional or psychological distress and hence the pianist would have to display empathy in such a situation in order to support the singer. Jones was also able to find the right balance between being the dominant force and being the secondary player in the artistic conversation.

To be a successful collaborative pianist also requires the skills and personality of a solo pianist, but with the ability to collaborate with another person. Margo Garrett, a professional collaborative pianist who is praised for her sensitive accompaniment and fluent technique, asserts from her own experience that she normally prepares for 15 recital programmes per year in comparison with a soloist's two or three in one year (Jepson 1986, 1). Garrett further states that a collaborative pianist not only needs the technique of an outstanding pianist, but also has the advantage of acquiring a broad knowledge of repertoire. The vocal accompanist may also be required to perform the same piece of music with different singers and therefore must be flexible in their interpretation of tempi, dynamics, touch and phrasing. Sometimes pianists have very little time to prepare for concerts or a competition, as was in fact the case at the Belvedere Competition, and in such a situation they would need to have highly proficient sight-reading abilities.

\section{SIGHT-READING}

A pianist who is an expert in sight-reading will have the advantage of being able to accept professional opportunities with little or no advance warning. They will therefore be able to adapt without hesitation in performances that require quick reflexive responses. They will also be able to scan the score far ahead with greater ease. With reference to sight-reading, Kopiez and Lee $(2006,97)$ write: 
"The unrehearsed performance of music, so-called sight reading (SR), is a skill required by all musicians. It is characterized by great demands on the performer's capacity to process highly complex visual input (the score) under the constraints of real-time and without the opportunity of error correction."

A number of pianists, including Margo Garrett (2018, 577), Marie Asner (1988, 20), James Sellers $(2003,15,17)$ and Philip Cranmer $(1970,35)$ have written widely about the importance of sight-reading as a necessary skill for any vocal collaborative pianist. Elizabeth Buccheri (orchestral pianist, teacher, vocal coach and accompanist) states that she often has to accompany 15 to 20 vocalists over the course of several hours without knowing what music she has to play until she walks on stage. She not only emphasises the significance of sight-reading skills, but also stresses the importance of recognizing the appropriate musical style. Because the opera repertoire is vast and it is impossible to know all the works, the challenge is always to sight-read accurately (Sellers 2003, 15, 17).

\section{UNDERSTANDING FOREIGN LANGUAGES AND THE RULES OF LYRIC DICTION}

Given the fact that opera is sung in many languages, experts emphasise that it is necessary for collaborative pianists to be familiar with the sounds and the technicalities of a range of languages (Hoekman 2004, 72). Many of the prescribed arias of the Belvedere competition were in English, Italian, German, French, Russian and Czech, and vocal coaches or répétiteurs usually become familiar with these languages through years of study. If collaborative pianists are not fluent in these languages, they will still need to familiarise themselves with the meaning of the arias that they will accompany. In doing so, they will be able to bring nuances to their playing that reflect the meaning of the text (Zeger 1997; Garrett 2018; Franks n.d.).

Martin Katz emphasises the fact that collaborating with a singer goes hand in hand with studying languages. The composer is first inspired by the text, which enables the singer to express those specific feelings and meanings in the words. Katz $(2009,21)$ stresses that although fluency in languages is not a prerequisite for a vocal collaborative pianist, the making of music together with the singer would be much easier when the pianist is familiar with the sounds and mechanics of the language of the song or aria. That is especially true of languages such as Russian and Czech, which are not often heard or spoken in Western contexts, making the meaning of the text and words in the repertoire very difficult to grasp.

In a situation where the pianist might have to coach the singers, they would also need to have an understanding of the rules of lyric diction. Timothy Hoekman $(2004,72)$ and Anne Epperson (Wenger 2008, 32) both emphasise how this knowledge would benefit the singer in the interpretation of the text. During the competition rehearsal time would be limited and the 
pianist would not necessarily have time to coach the singer (nor is it their duty to do so). However, the singer will certainly benefit from the pianist's knowledge of the meaning of the aria in order to produce a more thoughtful performance and to enhance the level of musicianship.

\section{LISTENING}

Listening skills in the art of accompaniment have been described as of the utmost importance for a collaborative performance. A number of experts including Beckman and Graves (1997, $20)$, Wenger $(2008,32)$ and Asner $(1988,20)$ have written extensively about the need to cultivate a keen listening ability that will allow the pianist to assist the singer by critically hearing sound and colour, and to pay special attention specifically where phrasing is of particular importance. Hoekman $(2004,72)$ asserts that intense listening is the most important characteristic of a vocal coach, seeing that they would need to provide feedback to the singer on what to improve and other aspects of ensemble.

\section{THE PIANIST SHOULD EMULATE THE SOUND OF AN ORCHESTRA}

Katz $(2009,153)$ highlights the importance for a pianist to emulate the sounds and feel of the instruments of an orchestra. He advises the pianist to listen sensitively to the orchestra in order to apply the different orchestral colours inventively and creatively (Katz 2009, 154). An accompanist who demonstrates the necessary pianistic skills and has the ability to project a sound like a full orchestra will certainly be an advantage for an opera singer (Zeger 1997, 2930). Furthermore, pianists should also strive to bring out individual instruments that play an integral part in the aural perception and emotional qualities of the aria (Sellers 2003, 15). Examples would be the pianist's ability to suggest the sound of the bassoon in Nemorino's "Una furtiva lagrima" from Donizetti's L'Elisir d'amore, or of the trombone emphasising Eboli's anguish and guilt in "O don fatale" in Verdi's Don Carlo or of the French horn mimicking Elisabeth's exuberance in "Dich teure Halle” from Wagner's Tannhäuser.

Big operatic scores are impossible to play on the piano and Garrett $(2018,577)$ therefore advises pianists to create their own reductions. This will likely entail an alteration of the score to make it more pianistic and more likely to reflect an orchestral quality.

\section{PIANO TRANSCRIPTIONS AND REDUCTIONS}

One of the most difficult skills the operatic collaborative pianist needs to master is to play reductions of orchestral accompaniments to concerti and operatic arias. A répétiteur needs to play orchestral reductions of pieces written originally for 20 to 100 musicians with only two 
hands. Listening to recordings will certainly help in understanding the original scoring. Cranmer (1970, 46-50) advises that pianists should be able to reduce an orchestral score to suit the shape of their hands and to a version which they can manage technically as well. If this is not possible, then a pianist should be able to omit (on the basis of an informed knowledge of the orchestration) parts in the reduction. Elizabeth Buccheri also advocates that if all the orchestral notes cannot be made to fit the two hands of a pianist, then the pianist should strive to remain as faithful as possible to the orchestral score when deciding what to leave out. Her advice is to first study the orchestral scores very intensely before working on the reduction and then decide what to leave out and what to play (Sellers 2003, 16). Furthermore, Margo Garrett's view is that pianists sometimes need to create their own "reductions" from a big operatic score that is written very unpianistically. In order for the reduction to be more pianistic and to create a better orchestral sound than what was originally reduced by the arranger, she suggests making "alterations" rather than "reductions" in order to achieve a better sound (Garrett 2018, 577).

Arrigo $(1998,2)$ adds that the accompanist needs to be acquainted with the traditional performance practices of the specific musical period of an opera aria. He mentions that a pianist additionally needs to understand the sentiment of the work, which entails examining the text and translation in order to interpret the piece as precisely as possible. The pianist who is playing a reduction from the Baroque era (1600-1750) needs to be inventive and use his creative skills as he will not be able to duplicate precisely what the orchestra plays. What comes to mind are the incredible arias "Agitata da due venti" by Vivaldi and "Disseratevi o porte d'Averno" by Handel. Both arias contain extremely melismatic coloratura passages and in many instances the vocal line is doubled a third apart by either the oboe or the violin. It would take an extremely dexterous pianist to mirror the coloratura passage and they would have to consider substituting chordal accompaniment instead, depending on their abilities. Cranmer recommends firstly always first referring to the full orchestral score before reducing the orchestral and continuo parts, and to take into account important harmonies, thematic material and instrumentation (Cranmer 1970, 48-49).

Because neither the text nor the translation is usually present in such a transcription, Arrigo (1998, 5) emphasises a few priorities for the accompanist who is transcribing. Knowledge of the text is required to produce a musical interpretation of the vocal literature with the benefit that the collaborative pianist can breathe, think and play like a singer. The transcriber needs to add additional phrase markings, dynamics, and articulations and breath marks in order to convey their awareness of the text and to enhance the soloist's interpretive efforts $(1998,5)$. 


\section{REPERTOIRE AND FLEXIBILITY}

Garrett $(2018,575)$ asserts that all professional vocal coaches/répétiteurs should have an allencompassing knowledge of vocal repertoire, which would be to their advantage when offering advice to singers. Asner $(1988,20)$ affirms that the accompanist must be familiar with all types of vocal repertoire and should also be able to transpose when necessary. They should also be able to familiarise themselves with a range of arias from different style periods and composers in order to capture the necessary performance practice aspects indicative of each style. These include being able to improvise in recitativo sections of the Baroque, Classical and early Romantic periods, understanding how rubato is applied to music from bel canto to Puccini and Verismo music and being able to ornament and articulate music appropriately from various styles.

Epperson $(2011,61)$ states that collaborative pianists need to apply the skills of flexibility, attentiveness and awareness during a performance to adjust according to the singer's needs, if necessary. A répétiteur may play the same aria with a number of singers on the same day and therefore needs to be flexible and be able to adjust tempi, phrasing, dynamics etc. to meet the requirements of each individual singer. During performances many singers may be vulnerable for a variety of reasons, including ill-health, performance anxiety, fatigue etc., and a pianist must in those circumstances support the singer and be attentive to changes in their singing stemming from such factors. Garrett commented during one of her classes on a student's accompaniment saying: "You can't follow the singer ... you have to walk down the street together. Bring out the bass more. Think of yourself as a conductor with a soloist" (Jepson 1986, 1).

\section{CROSS-CASE ANALYSIS: SUPERORDINATE AND CORRESPONDING THEMES}

In this study a cross-case analysis, as described by Creswell (2014, 199-200), enabled the authors to identify similar emerging themes from each case. Corresponding themes (themes that emerged among two or more but not all cases) were classified separately from superordinate themes, but will still be mentioned for a fuller understanding of the phenomenon. Our aim was to look for patterns in the cases to identify the main themes that emerged from each transcription of the in-depth interviews. Four superordinate themes were discussed by all five participants (of which two will be presented for the purposes of this article), while two participants mentioned another two corresponding themes (of which one will be presented). The one corresponding and two superordinate themes that emerged from the five participants' interviews are listed in Table 2. 
Table 2: One Corresponding and Two Superordinate Themes emerging from the Data

\begin{tabular}{|c|c|}
\hline Superordinate Themes & Raw Data \\
\hline Skill requirements of collaborative pianist & $\begin{array}{l}\text { Mathilda: } \\
\text { "I really try and sound like an orchestra and think differently } \\
\text { about the accompaniment." } \\
\text { Laetitia: } \\
\text { "You have to be prepared to adapt to the singer. You cannot } \\
\text { force your own ideas onto the singer because it is not really that } \\
\text { much of a collaborative scenario." } \\
\text { Elna: } \\
\text { "I think as an accompanist, it is actually a given to adjust to the } \\
\text { musical needs of the singer. As an accompanist I must be the } \\
\text { perfect 'safety-net' for the vocalist with whom I am walking on } \\
\text { stage." } \\
\text { José: } \\
\text { "There were no communication issues. I speak a lot of } \\
\text { languages and I could all of the time speak in their language } \\
\text { which made it very easier and pleasant for everybody. I spoke } \\
\text { Italian, Spanish, French, German and English. That helps } \\
\text { making the rehearsals more pleasant for everyone as they feel } \\
\text { that they could communicate with me." } \\
\text { Albie: } \\
\text { "So you have to be able to play well technically, but you have to } \\
\text { have an insight into what you see in front of you and the } \\
\text { elements of it. You have to fish out what is important and what } \\
\text { not. So it is a way of seeing a lot of detail and understand how } \\
\text { to organize it, that I think is important." }\end{array}$ \\
\hline Challenging aspects of the Competition & $\begin{array}{l}\text { Mathilda: } \\
\text { "If you work in an international opera house and you are the } \\
\text { répétiteur, sure then you would know all these arias which is } \\
\text { how they work it. They go to the opera houses and those } \\
\text { répétiteurs would play for this international competition. This } \\
\text { was a totally different set up than what they are used to." } \\
\text { Laetitia: } \\
\text { "The challenges were with the unknown repertoire." } \\
\text { Elna: } \\
\text { "Rehearsal times were very short and could not cover } \\
\text { everything." } \\
\text { José: } \\
\text { "Now five arias for one person are fine, but if you have six people } \\
\text { to play in one hour and each of them has five arias, then it is } 30 \\
\text { or } 40 \text { arias. I think that was quite special for this competition as } \\
\text { I don't think there are many others that work like that." } \\
\text { Albie: } \\
\text { "That was the other thing we wanted to make clear to the } \\
\text { organizers is that we are not five opera répétiteurs, but we have } \\
\text { other jobs and none of us has worked in an opera house in that } \\
\text { sense." }\end{array}$ \\
\hline Corresponding Theme & Raw Data \\
\hline Empathy for singers & $\begin{array}{l}\text { Mathilda: } \\
\text { "I am always sorry for them as their careers depend very much } \\
\text { on just getting positive reinforcement and not going through to } \\
\text { the next round can be devastating sometimes to a singer." } \\
\text { José: } \\
\text { "I remembered just talking to them by saying the usual thing 'you } \\
\text { did great' and 'it is more about people listening and not about } \\
\text { you'." }\end{array}$ \\
\hline
\end{tabular}

\section{DISCUSSION AND IMPLICATIONS}

The five participants are experienced vocal and instrumental collaborative pianists in South Africa. However, it is important to state that they are not full-time répétiteurs and were not familiar with the entire vocal repertoire (as répétiteurs in Europe might be). At present Cape 
Town Opera is the only full-time opera company producing full-scale works with orchestra, but because of budget restraints they do not employ full-time répétiteurs at present. As a result, the industry in South Africa does not provide the necessary infrastructure to support répétiteurs as one finds in Europe. Therefore, it would be logical to deduce that a répétiteur in Europe or America would be more familiar with the ever-growing operatic literature and would be well equipped to meet the demands of this specific competition. Franks (Franks n.d., 50) supports this argument that répétiteurs who are appointed on a contract basis at opera houses in Europe (and abroad) are able to meet the requirements of being excellent pianists and répétiteurs, especially during a competition such as the Belvedere. Franks states that it is indispensable for a répétiteur to have a vast knowledge of the repertoire and to be able to play repertoire from Handel to Stockhausen. In order to mitigate the challenges of the competition, especially the short rehearsal time and the anxiety induced because of the uncertainty of the repertoire to be played, the pianists had to rely on well-honed skills developed throughout their careers.

As the data emerged it became clear that the pianists experienced that their acquired skill set helped them to overcome the challenges of the competition. These skills included knowledge of different languages, repertoire and lyric diction; excellent sight-reading abilities; knowledge of the art of orchestral reduction and repertoire; and having an exceptional piano technique. These skills corresponded to those mentioned in the literature (Arrigo 1998; Asner 1988; Cranmer 1970; Garrett 2018; Katz 2009; Kopiez and Lee 2006; Sellers 2003; Wenger 2008; Zeger 1997). The five participants highlighted the skill of sight-reading as an essential prerequisite for a proficient accompanist, especially for a vocal accompanist. The participants highlighted the importance of sounding like an orchestra. Mathilda stated that she made use of different techniques to simulate orchestral colours or an instrument, while taking into account the limitations of the piano. She stated that an experienced répétiteur will always aim to let the singer feel secure by providing support as if an orchestra is accompanying them.

Albie's data showed a unique approach towards making the piano sound like an orchestra. He firstly had to make sense of the details of the orchestral score in order to understand what will be the important parts to play. Katz $(2009,154)$ states that accompanists must simply "cut" out any extra material in the accompaniment to make the aria scores more playable and they need to develop a feeling for timbres and colours in order to imitate the sounds of the orchestra.

Apart from having the ability to sound like an orchestra, pianists often find themselves in situations where they do not have an orchestral reduction of the opera and have to be able to transcribe directly from the full orchestral score of the opera. The literature therefore places a great deal of emphasis on the skill and knowledge for an accompanist to be able to transcribe their own versions of orchestral scores. The way Albie describes his process of analysing the 
most important parts of the orchestral score suggests that while he may not have had to transcribe from a full score for the competition, he needed to have knowledge and understanding of the full score before he played the reduction in order to imitate the required orchestral sounds. His aim was to reflect the most important instruments in the orchestra, even if those instruments were not reflected in the reduction, in a way creating his own transcription while using the colours of the piano to best bring out the orchestral colours. Elizabeth Buccheri (Sellers 2003, 15) teaches her students that an essential aspect of transcription is not to play exactly what is written in an orchestral reduction, but to study the orchestral score with care and to gain insight into the orchestral score to see what is important and what is not.

In order to help mitigate the stress experienced by the singers in the competition, Elna, José and Albie indicated that they had to show flexibility, to adjust to the singer's performance, to form a perfect "safety-net" and to support the singers musically. Margo Garrett (Jepson 1986, 1) stated that a professional accompanist must keep his/her focus on the performer during a performance and needs to be a sensitive and responsive partner. Mathilda highlighted the unpredictability of singers who can perform totally differently on stage to what was rehearsed. As an example she refers to singers who might need differing lengths of time for breathing and phrasing, or singers who do not count.

Pianists who are fluent in foreign languages have a huge advantage not only in communicating with singers from other countries during the competition, but also allowing them to better interpret the text of the aria. However, if a pianist is not fluent in these languages, a working knowledge would help in the overall interpretation of the arias. What the authors mean by this is that many singers and pianists might not be able to carry a conversation with a mother-tongue French, Italian or German speaker, but when presented with a score they will have enough knowledge of the language to understand what is written on the page. Lanners $(2010,25)$ asserts that in accompanying vocalists, the meaning of the sung text will serve as an interpretative guide to performing the music. Albie, in particular, stipulated the essence of being a vocal accompanist, namely having an interest in the meaning of the words of an opera aria and to understand the dramatic context as the drama unfolds in the opera. Roger Vignoles, a world-renowned accompanist with years of experience, states that to be a vocal accompanist requires knowledge and the ability to create colours and different moods in the music, as well as the ability to determine the correct balance between different soloists (Fairman 2015).

Although providing emotional support for singers is not often described as one of the typical skills required of a collaborative pianist, the data reflected that empathy for singers was in fact associated with the skills required to enhance collaboration in this competition setting. This corroborates research that higher empathy is correlated with better ensemble performance 
(Keller 2014; Novembre et al. 2012). The authors would like to suggest that providing emotional support for the singer should be considered just as important as sight-reading or transcribing from the score. Hoekman $(2004,91)$ stated that each singer has his or her own weaknesses, interests and strengths, which can be challenging for them and they will thus need the accompanist's emotional support. The participants described the support they provided as going beyond the stage performance to the post-performance moment as well. They provided emotional support to the singers, whose careers could be greatly influenced by the outcome of this competition.

\section{CONCLUSION}

In newly created coursework specialising in operatic collaborative piano, modules would need to be included that allow the students to accompany singers in opera rehearsals as well as in individual voice lessons, thereby also learning about the technical and interpretative nuances of an aria from the perspective of a voice teacher. By playing for numerous rehearsals and lessons, students will be able to develop their sight-reading skills, especially in private rehearsals with singers. Prospective operatic collaborative piano students should also be able to receive coaching, lessons and master classes from conductors and experienced répétiteurs (thereby also strengthening their own abilities as vocal coaches). They should be able to take courses that allow them to explore standard classical and contemporary opera literature and performance practice. Modules also need to include courses that teach collaborative pianists improvisation (useful in Baroque, Classical and early Romantic recitativo), the basic rules of lyric diction in foreign languages (especially Italian, French and German), and the ability to reduce opera scores pianistically and to meet the individual technical needs of the pianist. Courses should also be included that facilitate and help nurture empathy when working with singers. In addition to this newly proposed coursework, attention will also have to be paid particularly to the lack of Black students enrolled for instruction in piano courses.

Roos (2010) stated that an increase in the amount of Black singers trained at tertiary institutions in South Africa was inevitable because of the excellent training received. In the last ten years, enrolment in classical singing at various tertiary institutions including North-West University, the University of Cape Town and the University of Kwazulu-Natal have increased and singing students have exceled at various national and international opera competitions. In the last ten years many South African Black singers have also established careers either freelancing or as contract singers at opera houses in Europe and the US (Teto 2020). Unfortunately, such an increase in capacity among Black pianists has not transpired. Consequently, there would always be a lack of support for singers if nothing is done to build 
capacity for operatic collaborative pianists especially among Black South Africans. In order to fully change the narrative that opera is associated with the "musical preferences of the upperclass white population of the country" (Roos 2014, 2), focus needs to be given to the capacity development of Black directors, conductors and répétiteurs.

Prof. Tinus Botha, Associate Professor at North-West University and president of the World Piano Teachers Association states that enrolment among Black pianists at tertiary institutions remains minimal and often very few Black pianists take part in UNISA examinations or similar music offerings countrywide. He attributes this to the fact that the development of young prospective Black pianists especially in townships and rural areas is hindered due to no accessibility to pianos or keyboards in their communities. "Since singers, trumpeters and violinists always have access to their instruments, they can practice more easily and develop their skills" (Botha 2020). Nuzuko Teto, a professional singer and lecturer in voice at the Durban University of Technology states that because no répétiteurs are being trained in Durban and the surrounding areas, pianists with whom she can collaborate are few and far between. "There are no pianists around who knows the operatic repertoire well enough to accompany me and the one or two pianists in the area (who are not répétiteurs) need a lot of time to familiarise themselves with the demands of the vocal repertoire" (Teto 2020).

Teto states that if one hears of Black pianists in predominantly Black townships, they are often self-taught (Teto 2020). Michael Dingaan who serves as an advisor in the Schools Enrichment Program of the Department of Basic Education confirms this fact and adds that there is a rudimentary issue with the lack of music being taught in primary and secondary schools especially in townships and in rural areas. Music subjects are often only taught at magnet schools and many students who live far from these schools do not have access to instruction. He states that the reason why singers from those areas have been so successful is because of the passion and dedication of teachers, oftentimes many who may not be qualified or trained in classical singing. "Many times the Maths teacher or the Biology teacher has a passion for singing and then also conducts the choir. Because of their dedication and will, they instil a knowledge and love for singing among learners in their communities. Unfortunately, the same cannot be said for the piano" (Dingaan 2020). Dingaan also confirms that a lack of accessibility to pianos or keyboards plays a role in the lack of training and development of young Black pianists.

Since young Black Pianists are often self-taught and lack instruction in schools from an early age, they will often not always be able to meet the necessary pre-requisite standards of technical proficiency demanded for entry to universities. Singers who come from similar communities already arrive at universities with the necessary technical foundation in order to 
qualify for a degree or diploma. These skills are often learned from teachers (many of whom are not trained singers) and in community choirs. If universities wish to develop capacity among Black répétiteurs in South Africa, then they would have to tailor recruitment activities to involve training for pianists in their formative years already. Possibly the Department of Basic Education and the private sector could partner to provide more pianos to children in townships and rural areas where they do not have access to instruments. Besides providing instruction or master classes to teachers in those communities, universities could also play a role in the maintenance of their pianos. If an effort is not made to address the lack of capacity development for répétiteurs in South Africa from an early age, then a plan to develop curricula in tertiary institutions for operatic collaborative pianists would be to no avail. A limitation of this study is that it does not focus on the experiences of students who currently receive informal training towards répétiteur work. In further studies researchers could explore those experiences and also examine how new modules can be introduced in current undergraduate and postgraduate courses in South African institutions.

\section{ACKNOWLEDGMENTS}

This research was conducted by the (name withheld for Peer-Review) as part of a Doctoral Dissertation.

\section{NOTES}

1. ("How the Hans Gabor Belvedere Singing Competition Became the Biggest Singers' Stock Exchange in the World" n.d.)

2. Ibid.

3. Ibid.

4. Information on biographical details via communication with the participants and online sources.

\section{REFERENCES}

Arrigo, R. J. 1998. Transcription of Vocal Literature for Solo Instrument and Piano Accompaniment: A Unique Challenge for Accompanists. Coral Gables, FL: University of Miami.

Asner, Marie A. 1988. “Accompanist and Vocalist: Partners in Music.” American Music Teacher 37(5): 20-21.

Beckman, Seth and Jeffrey Graves. 1997. "Promoting Thoughtful Musical Collaboration." The American Music Teacher 46(4): 20-24.

Botha, Tinus. 2020. Interview on 10 January 2020.

Brunelle, Elise. 2019. General Manager of Cape Town Opera [telephonic correspondence] Telephone.

Cranmer, P. 1970. The Technique of Accompaniment. London: Dobson Books.

Creswell, J. W. 2014. Research Design: Qualitative, Quantitative, \& Mixed Methods Approaches. Los Angeles: SAGE. 
Creswell, J. W. and C. Poth N. 2017. Qualitative Inquiry \& Research Design: Choosing among Five Approaches. Los Angeles: SAGE.

De Koker, Jessica. 2019. "Collaborative Pianists in South Africa: Comparative \& Practice-Based Perspectives with Reference to Musical Theatre.” Masters Thesis, Stellenbosch, RSA: University of Stellenbosch.

Demarest, A. 1964. "Gerald Moore an Interview." American Music Teacher 14(2): 28-29.

Dingaan, Michael. 2020. Interview 0n 10 January 2020.

Dzorkpey, T., H. Potgieter, and J. Kruger. 2013. "The Quest for Tirisano: Challenges of Implementation in the South African School Choral Eisteddfod." Musicus 41(1): 22-26.

Epperson, Anne. 2011. "The Prince of American Collaborative Pianists." The American Music Teacher 60(3): 18-20.

Fairman, R. 2015. "The Complex Art of the Accompanist." 2015. https:/www.ft.com/content/ 0578b102-1e74-11e5-ab0f-6bb9974f25d0.

Franks, R. n.d. “Opera's Unsung Heroes.” BBC Music 20(4): 48-51.

Garrett, M. 2018. "The Art and the Skills of Vocal Coaching." The Journal of Singing 74(5): 575-78.

Garrett, M. and C. Reynolds. 2017. "How to Create the Best Audition Binder." The Journal of Singing 73(5): 557-60.

Guest, Greg, Emily E. Namey, and Marilyn L. Mitchell. 2020. Collecting Qualitative Data: A Field Manual for Applied Research. 55 City Road, London. https://doi.org/10.4135/9781506374680.

Hoekman, T. 2004. "What Is Vocal Coaching?" American Music Teacher 54(2): 72, 91.

Hornsveld, Mathilda. 2017. 35th Belvedere International Singing Competition. Personal interview on 30 October 2017.

"How the Hans Gabor Belvedere Singing Competition Became the Biggest Singers' Stock Exchange in the World." n.d. http://www.belvedere-competition,com/about (Accessed 30 July 2016).

Jepson, B. 1986. "In Concert: Playing Second Fiddle: The Accompanist's Plight.” Wall Street Journal 8 May 1986. Eastern edition.

Katz, Martin. 2009. "The Complete Collaborator: The Pianist as Partner." /z-wcorg/. https://search.ebscohost.com/login.aspx?direct $=$ true \&scope $=$ site $\& d b=$ nlebk\&db=nlabk\&AN=19 10942.

Keller, Peter E. 2014. "Ensemble Performance: Interpersonal Alignment of Musical Expression.” In Expressiveness in Music Performance: Empirical Approaches across Styles and Cultures, 26082. Oxford: Oxford University Press. https://pkpublications.weebly.com/uploads/1/1/8/3/ 11835433/keller_in-press_ch15_expression-in-ensemble-performance.pdf.

Kopiez, Reinhard and Ji In Lee. 2006. "Towards a Dynamic Model of Skills Involved in Sight Reading Music.” Music Education Research 8(1): 97-120. https://doi.org/10.1080/14613800600570785.

Kumar, Ranjit. 2014. Research Methodology. London: SAGE Publications: SAGE Publications Ltd.

Lanners, Thomas. 2010. "Equal Opportunity Coaching: Tips for Coaching Vocal and Instrumental Collaborations With Pianists." American Music Teacher 59(5): 22-25.

Maree, Kobus. 2007. First Steps in Research. Pretoria: Van Schaik.

McEwan, C. 2016. "Full Newsletter: 35th International Hans Gabor Belvedere Singing Competition Finals Tomorrow." http://www.cpo.org.za/belvedere-singing-competition-newsletter/.

Moore, G. 1944. The Unashamed Accompanist. New York, NY: The MacMillan Company.

Novembre, Giacomo, Luca F. Ticini, Simone Schütz-Bosbach, and Peter E. Keller. 2012. "Distinguishing Self and Other in Joint Action. Evidence from a Musical Paradigm." Cerebral Cortex 22(12): 2894-2903. https://doi.org/10.1093/cercor/bhr364.

Pooley, T. 2020. "Singing in South African Schools." In The Routledge Companion to Interdisciplinary Studies in Singing, Volume II: Education. New York, NY: Routledge. 
Reid, Katie, Paul Flowers, and Michael Larkin. 2005. "Exploring Lived Experience." The Psychologist 18(1): 20-23.

Roos, Hilde. 2010. "Opera Production in the Western Cape: Strategies in Search of Indigenization." Doctoral Thesis, Stellenbosch, South Africa: The University of Stellenbosch.

Roos, Hilde. 2014. "Remembering to Forget the Eoan Group - the Legacy of an Opera Company from the Apartheid Era." South African Theatre Journal 27(1): 1-18. https://doi.org/ 10.1080/10137548.2014.847005.

Sellers, J. 2003. "Unsung Heroes at the Piano for Soloists and Conductors: An Interview with Elizabeth Buccheri." Clavier 42(9): 15-17.

Smith, Jonathan A., Paul Flowers, and Michael Larkin. 2009. "Interpretative Phenomenological Analysis: Theory, Method and Research." Qualitative Research in Psychology 6(4): 346-47. https://doi.org/10.1080/14780880903340091.

Teto, Nozuko. 2020. Interview on 10 January 2020.

Tracy, S. J. 2013. Qualitative Research Methods: Collective Evidence, Crafting Analysis, Communicating Impact. Oxford: Wiley-Blackwell.

Van Schalkwyk, Albie. 2017. 35th Belvedere International Singing Competition. Personal Interview on 18 November 2017.

Wenger, Janice. 2008. "Passion for Collaboration.” American Music Teacher 57(4): 30-34.

Zeger, B. 1997. "The Life of a Rehearsal Pianist: Helping Hands.” Opera News 61(9): 28-30. 